\title{
LA CREACIÓN DE EMPLEO, MISIÓN -Y VISIÓN- DE EMPRENDEDORES SOLIDARIOS
}

\author{
Antonio Macías \\ Doctor en Ciencias Económicas y Empresariales, Universidad Complutense, Madrid
}

\section{Resumen:}

Las nuevas realidades económicas y de producción nos están despertando de un sueño vivido durante la segunda mitad del siglo pasado en el que las estructuras empresariales y de gestión, los derechos y beneficios logrados para los trabajadores, las vinculaciones entre empresa-trabajador-producto se empiezan a romper como consecuencia de la irrupción en nuestras vidas de las nuevas tecnologías al servicio de todas las personas. Sin embargo y pese a la simplificación de trámites y gestiones que dichas tecnologías pueden suponer, en España no se termina de ver esa ventaja, al contrario que en otros países de nuestro entorno, sobre todo en el ámbito de los que se deciden a iniciar una nueva actividad empresarial. Al contrario, la implantación de éstas en las empresas privadas está facilitando una nueva forma de trabajo: el tele-trabajo. La conexión instantánea con cualquier y desde cualquier punto a una central o con un cliente, se encuentren donde se encuentren empresa y/o cliente o proveedor, va a suponer un cambio en las estructuras empresariales que puede beneficiar a muchos, acercando, promoviendo y facilitando el comercio y la gestión en las empresas, al eliminar viejas estructuras de costes elevados. Pero como siempre, cuando se modifican estructuras, se generará un coste social y personal que no puede ser obviado.

Palabras clave: Desarrollo económico - Desempleo - Innovación - Emprendedor Autoempleo

\section{INTRODUCCIÓN}

Con más medios, más saber, más técnicas físicas y sociales que nunca, nuestra "generación del paro" no es capaz de resolver este problema. Se intentan actuaciones basadas en el criterio "más de lo mismo": más beneficios fiscales o mayores subvenciones, más inversiones en I+D, más incentivos a la capitalización de empresas...

O, en el caso de las medidas sociolaborales, en el criterio opuesto, "menos de lo mismo": menos seguridad en el empleo, menos costes salariales, menos prestaciones sociales...

Tales medidas, lejos de resolver el problema, están creando otros más graves.

Recibido: 15/03/2001---Aceptado: 14/05/2001---Publicado: 01/12/2001

http://www.revistaccinformacion.net/publicados.htm 
La tozudez de los hechos, que nos han conducido a una situación crítica inadvertidamente para algunos pero ya evidente en campos históricamente precursores, como las Bolsas-, debiera sugerirnos un enfoque nuevo, basado en el poder de la imaginación.

Es decir, dejando de una vez de dar vueltas a "lo mismo". Al fin y al cabo, "crisis" significa etimológicamente "decisión".

\section{UNA NUEVA SITUACIÓN}

El desarrollo, dice Naisbit, ya no depende tanto del capital como de las ideas. Podemos conseguir capital pero, ¿cómo conseguir ideas? Porque es necesaria una nueva propuesta, dadas las características del escenario previsible del empleo en los próximos años.

Efectivamente, el panorama previsible es sencillamente el opuesto al de los años 60, el comienzo de nuestro despegue industrial. El pretendido "hombre organización" de la generación del Seat 600 , del trabajo por cuenta ajena hasta los 65 años en organizaciones estables y con pensión garantizada, está tocando fondo, por causas diversas.

Ante todo por la innovación tecnológica permanente. Las nuevas tecnologías están eliminando, rápidamente y en gran proporción, la participación de seres humanos en la producción de bienes y servicios. A ello se une la creciente globalización de los mercados y la producción, que actúa en el doble frente de la competitividad internacional y de la transferencia del empleo a países en desarrollo.

La nueva situación está reduciendo notablemente la duración del periodo tradicional del trabajo por cuenta ajena en el "primer mundo". Los nuevos límites tienden a acomodarse entre los 25 y los 45 años de edad. Esta asimismo nueva realidad, en la que prácticamente queda reducido a la mitad el tiempo del empleo tradicional, requiere claramente este enfoque distinto al "más o menos del mismo". Recurramos a lo original; es decir, volvamos al "origen". A los sentimientos primordiales frente a la dureza de las situaciones: el espíritu emprendedor y la solidaridad.

\section{RECONOCIMIENTO DEL VALOR DE LOS EMPRENDEDORES}

La propuesta de Schumpeter tiene que ganar plena vigencia. Hay que situar a los emprendedores en el centro de la vida social, económica y política ("emprendedor" no quiere decir necesariamente "empresario" y menos "capitalista", téngase en cuenta).

Parece evidente que en época de paro generalizado, el protagonismo pase a las personas que estén dispuestas a desempeñar este papel, puesto que es igualmente evidente que, aunque hay que contar con ella, no es la voluntad política sino la de los emprendedores la que crea riqueza y empleo. 


\section{LA CREACIÓN DE EMPLEO, MISIÓN -Y VISIÓN- DE EMPRENDEDORES SOLIDARIOS}

Las medidas económicas que se tomen han de ser en el sentido de proporcionar un amplio terreno reglamentario en el que han de jugar los emprendedores. De éstos y de ello depende, dramáticamente, la aparición de puestos de trabajo ahora inimaginables.

Como emprendedores actúan, según el economista austríaco, quienes aportan nuevas combinaciones productivas: introduciendo nuevos bienes o servicios, 0 métodos de fabricación, abriendo nuevos mercados, utilizando de formas diferentes las materias primas o desarrollando nuevos tipos de organización.

A todo ello se añaden nuevas formas de pensar que les alejan del concepto de simple "empresario":

- La expresión de una necesidad vital y vocacional, antes que una orientación al mercado.

- El predominio del servicio, a través de la realización personal, sobre el beneficio.

- El sentido artesanal de la obra bien hecha, sobre la producción en serie.

- La tendencia al trabajo "en casa", con apoyo de las nuevas tecnologías, en lugar de las concentraciones humanas en centros empresariales.

En el cuadro adjunto se hace un retrato robot del emprendedor, mediante siete de las características que mejor le definen.

Los emprendedores desarrollan sus habilidades y conocimientos, que venden directamente, para satisfacer necesidades -no necesariamente "demandas"sociales. Sus fórmulas son el autoempleo, la creación de redes profesionales, la iniciación de microempresas, la actuación como profesionales liberales... En definitiva, trabajando de forma autónoma. Para empezar, emprender el propio empleo es sobre todo una actitud. Una forma de pensar la actividad profesional, posiblemente hasta entonces en manos ajenas; como una ocupación desempeñada vitalmente, tras recuperar la confianza en sí mismo.

\section{EL PARO ACTUAL ES SOCIALMENTE ESTRUCTURAL}

En esta vuelta al origen del examen de los problemas, advertimos que el paro actual no es cuestión de capital, pero es que ni siquiera es sólo económico. Las bonanzas pueden suavizarlo, pero nunca acabar con él. $\mathrm{Ni}$ siquiera millones de emprendedores podrían conseguirlo sólo económicamente. Al recuperar la mentalidad descrita más arriba, hay asimismo que liberar valores que fueron ridiculizados, el gusto por la obra bien hecha y también la lealtad y la solidaridad, como medio de dar sentido a la vida.

Son criterios o valores que reafirman la sociedad civil como una actitud mental y una forma de entender la vida; que no sólo permiten a cada ciudadano desplegar sus posibilidades, su increíblemente rico potencial, sino hacerlo en una sociedad de la que se siente partícipe, con la que se siente solidario y en la que se siente protagonista en vez de víctima.

\section{SIETE PROPUESTAS PARA LA ACCIÓN}


Al llegar aquí, se hace inevitable preguntarse: todo esto ¿Cómo puede traducirse en planes concretos de acción?.

La fórmula de validez universal probablemente no existe. Sin embargo, veamos algunos de los puntos sobre los que cabría hacer el ejercicio mental y vital necesario:

1. Distribución solidaria del trabajo disponible.

En la línea del trabajo a tiempo parcial, el reparto del trabajo o las ocupaciones alternativas. Estas posibilidades han sido formuladas tímida mente por la clase política, sin haber instrumentado antes la forma de paliar la disminución de las rentas salariales individuales. El resultado ha sido el rechazo de unos y el empecinamiento de otros, que hacen imposible la visión de la transición imprescindible.

2. Apoyo a los futuros emprendedores.

El 30\% de los jóvenes estudiantes, según estudios llevados a cabo, muestran capacidades potenciales para ser emprendedores. Sería preciso seleccionarlos, estimularlos, prestarles apoyo para que apliquen sus dotes.

Desde hace algunos años, estamos desarrollando, por nuestra parte, círculos de emprendedores con alumnos de los últimos cursos de carreras universitarias. El mensaje es "tú puedes", a condición de que cambies la dirección del punto de mira y salgas de lo que, si no, pueden ser fábricas universitarias de parados con un proyecto vital y profesional distinto a buscar empleo por cuenta ajena.

3. Solidaridad de las administraciones publicas con los emprendedores.

La promoción de emprendedores puede caer en terreno estéril si éstos encuentran barreras, a menudo infranqueables, para desarrollar sus proyectos profesionales.

La propuesta "ventanilla única" supuso una esperanza que sigue sin realizarse. Crear una empresa requiere más de 50 permisos, con trámites que llevan hasta un año y un desembolso medio superior a 500.000 pesetas. Esta perspectiva puede acabar frustrando al emprendedor más impenitente.

La inconcreción de la ventanilla única es un caso de falta de solidaridad con los emprendedores. Los diferentes grupos de presión -las diferentes administraciones, los funcionarios, los colegios profesionales, etc.- desean ejercer indebidamente su poder antes de cederlo a los emprendedores, únicos protagonistas merecidos de la historia.

4. Solidaridad con los emprendedores que libremente deseen llevar a cabo actividades de utilidad social.

La gran paradoja de nuestro tiempo está en la contradicción entre el elevado número de desocupados y las crecientes -o crecientemente advertidasnecesidades humanas.

Cuando más de 1.000 millones de personas (muchas de ellas entre nosotros) pasan hambre y hay más de veinte guerras en curso, con un medio ambiente en grave deterioro, etc., parece difícil admitir que esté todo hecho, que no haya posibilidades de ocupación para los parados

5. Solidaridad entre generaciones.

Se trata de canalizar la experiencia y relaciones acumuladas 120 por los mayores a favor de los jóvenes. Los jóvenes pueden poseer el conocimiento 


\section{LA CREACIÓN DE EMPLEO, MISIÓN -Y VISIÓN- DE EMPRENDEDORES SOLIDARIOS}

básico necesario, el dominio de las nuevas tecnologías, pero carecen de cierta sabiduría y la experiencia que son fruto de los años.

La creación de puntos de encuentro entre ambos colectivos, para el desarrollo de proyectos innovadores, permitiría cubrir las carencias de los más jóvenes.

6. Solidaridad con los parados de larga duración, aquellos que sufren la frustración de haber perdido el trabajo y encuentran serias dificultades, especialmente por razones de edad, para encontrar un nuevo empleo. Existe un trauma, que no puede ser desestimado, de sentirse solos, sin la seguridad de una empresa al menos supuestamente sólida y estable, a la que estaban habituados. Por ello, hay que prepararles para un futuro diferente, permitiéndoles desarrollar capacidades que puedan ofrecer directamente en diferentes ámbitos, de modo que puedan "cuidar de sí mismos". No hay que desestimar su encaje especial como empleados preparados de los nuevos emprendedores.

7. Solidaridad como el valor clave de la nueva cultura emprendedora, basada en criterios y valores que favorezcan el espíritu emprendedor, en vez de cerrarlo a nuestro paso. Y desterrando la idea del dinero fácil, la corrupción, la llamada "cultura del pelotazo", de una vez para siempre. Sustituida por los nuevos valores de los proyectos creativos llevados a cabo de forma solidaria, de las estructuras abiertas.

Con estas propuestas, pretendemos abrir un debate sobre la necesidad urgente y la posibilidad próxima de crear un clima de estabilidad y entusiasmo por el futuro de este país.

\section{Retrato robot del emprendedor:}

1. Anticipa metas y los planes para lograrlas.

2. Trabaja proactivamente.

3. Es creativo. Combina ideas ele forma no usual.

4. Percibe su entorno activamente. Investiga necesidades sociales -mercadosno o insuficientemente cubiertas

5. Obtiene adhesiones. Forma equipos de colaboradores, a los que motiva y organiza.

6. Soluciona problemas y toma decisiones con una moderada aceptación de riesgos.

7. Es buen comunicador. Sabe "vender" sus ideas.

8. Pone en práctica sus ideas no discursivamente sino a través de proyectos. 